\title{
Aortic coarctation decision making comes of age
}

\author{
Emile Bacha, MD
}

From the Division of Cardiac, Thoracic and Vascular Surgery, New York-Presbyterian/Columbia University Medical Center, Morgan Stanley Children's Hospital, New York, NY.

Disclosures: Author has nothing to disclose with regard to commercial support.

Received for publication Nov 12, 2017; accepted for publication Nov 15, 2017; available ahead of print Dec 7, 2017.

Address for reprints: Emile Bacha, MD, Division of Cardiac, Thoracic and Vascular Surgery, New YorkPresbyterian/Columbia University Medical Center, Morgan Stanley Children's Hospital, 3959 Broadway, New York, NY 10032 (E-mail: eb2709@cumc.columbia.edu).

J Thorac Cardiovasc Surg 2018;155:1184-5

$0022-5223 / \$ 36.00$

Copyright $(c) 2017$ by The American Association for Thoracic Surgery

https://doi.org/10.1016/j.jtcvs.2017.11.058

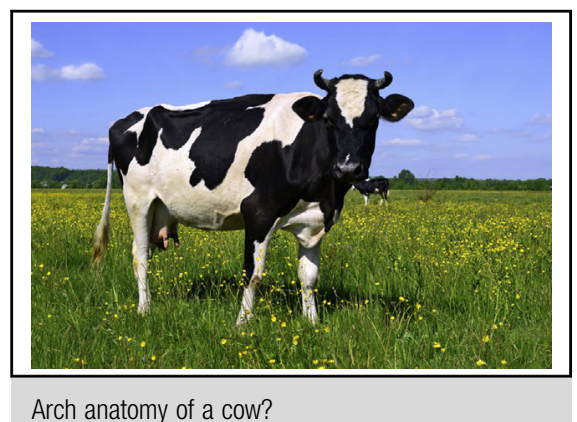

Central Message

A paradigm shift in the management of aortic coarctation comes from showing that a bovine arch should be actively looked for by preoperative imaging and is a significant risk factor for recoarctation.

See Article page 1178 . of the Journal by Turek and colleagues ${ }^{2}$ is one of those interesting studies that originate from an "aha moment" in the operating room, creating an idea in the surgeon's mind that ultimately results in a retrospective look at a specific patient cohort and, sometimes but not always, offers a gratifying validation of this surgical "hunch." It is amazing, when one really thinks about it, how many surgical advances, from the first patent ductus arteriosus ligation to the Trendelenburg operation to the development of the heart-lung machine, came about through such impetus. Even though the study of Turek and colleagues ${ }^{2}$ is a retrospective review of only 49 patients, it is a solid study. The follow-up is nearly up to date, and all the imaging studies were rereviewed by blinded physicians. At face value, it could be dismissed as "only" demonstrating a risk factor for recoarctation, but in fact it is of significance because it will help with decision making in 2 major ways:

1. It refines our prognostic ability when discussing surgical results with families and changes practice patterns by pushing surgeons toward a sternotomy repair, as opposed to a left thoracotomy approach, when a bovine arch is present.

2. It contains interesting information for cardiac imagers, in that a bovine arch was frequently underdiagnosed in routine arch echocardiographic imaging (bovine arch was diagnosed in $6 \%$ of patients by routine echocardiography vs $28 \%$ on targeted image review). This implies either that the routine echocardiography obtained before each coarctation surgery has to become more specific or that other imaging modalities, specifically cardiac computed tomography or magnetic resonance imaging, have to be used more liberally.

Regarding the first point, some pediatric cardiac surgical groups have turned to using an on-pump sternotomy repair as their primary repair technique for neonatal aortic coarctation. ${ }^{3}$ My own group has also been inclined, when in doubt about the smallness of the aortic arch, in particular the proximal arch, to go to a sternotomy repair. For help with decision making, we often use, as do others, $z$ scores for arch diameter of less than -2 , calculated by relating the specific segment of the aortic arch in question to normal values, or, as do Turek and colleagues, ${ }^{2}$ a definition of a hypoplastic proximal arch of a diameter less than body weight (in kilograms) $+1 \mathrm{~mm}$ at the left common carotid artery. None of these criteria are used as final parameters, however, and decisions are ultimately made on the basis of surgical "instincts" or "impressions" - in other words, subjective criteria, informed by both personal surgical experience and institutional memory. This study, at least, provides us with one objective criterion to use in this setting.

Finally, the total (clinical) cost of recoarctation over a lifetime is worth discussing. What if a recoarctation "only" requires a percutaneous balloon dilation a few years after the original repair? The pediatric cardiac surgical community is not even close to a consensus as to how best to protect the brain in infant aortic arch surgery. Some of the as yet unresolved questions include to which temperature to cool and whether to perfuse the brain (selective cerebral perfusion) or not (deep hypothermic circulatory arrest). In 
other words, is an on-pump sternotomy repair, with likely a very small yet not nil accompanying risk of brain damage, worthwhile just to avoid a recoarctation? Those are the difficult questions that we should try to answer. In the meantime, Turek and colleagues ${ }^{2}$ have added real value to the management of infants with aortic coarctation by showing that a bovine arch needs to be actively looked for and excluded by preoperative imaging and that it is a significant risk factor for recoarctation.

\section{References}

1. Layton KF, Kallmes DF, Cloft HJ, Lindell EP, Cox VS. Bovine aortic arch varian in humans: clarification of a common misnomer. AJNR Am J Neuroradiol. 2006; 27:1541-2.

2. Turek JW, Conway BD, Cavanaugh NB, Meyer AM, Aldoss O, Reinking BE, et al Bovine arch anatomy influences recoarctation rates in the era of the extended endto-end anastomosis. J Thorac Cardiovasc Surg. 2018;155:1178-83.

3. Mery CM, Guzmán-Pruneda FA, Carberry KE, Watrin CH, McChesney GR, Chan JG, et al. Aortic arch advancement for aortic coarctation and hypoplastic aortic arch in neonates and infants. Ann Thorac Surg. 2014;98:625-33; discussion 633. 